rial infections? In view of the critical protective role played by A-ICs, do their sister cells, B-ICs, play a complementary role in combating infection? Despite any lingering questions, the results of this study are important and reveal how a specialized kidney cell, previously implicated in acid-base homeostasis, combats bacterial infections of the urinary tract.

Highly specialized epithelial cells are dispersed on various mucous membranes and are involved in maintaining the integrity of the mucosal barrier, mediating secretion, selective absorption, or transcellular transport. The revelation by Paragas and collaborators that, in addition to maintaining acid-base homeostasis, kidney A-ICs play a key role in abrogating bacterial infection in the urinary tract (7), has implications for human renal diseases. For example, human diseases that involve A-IC dysfunction, such as chronic distal renal tubular acidosis, are characterized by recurrent UTIs and pyelonephritis (15). As the aged population has dramatically grown in recent years, recurrent UTIs have become a substantial clinical problem in hospitals and nursing homes (16). Antibiotics are increasingly ineffective for combating UTIs; therefore, harnessing and boosting the innate anti- microbial properties of cells in the urinary tract, such as A-ICs, may become viable therapeutic alternatives.

\section{Acknowledgments}

The authors were funded by NIH grants U01-AI082107, R01-AI096305, and R56DK095198 and by a block grant from Duke-NUS, Singapore.

Address correspondence to: Soman N. Abraham, Department of Pathology, Duke University Medical Center, Box 3712, Durham, North Carolina 27514, USA. Phone: 919.684.3630; Fax: 919.684.2021; E-mail: soman.abraham@duke.edu.

1. Chromek M, Brauner A. Antimicrobial mechanisms of the urinary tract. J Mol Med (Berl). 2008; 86(1):37-47.

2. Chromek M, et al. The antimicrobial peptide cathelicidin protects the urinary tract against invasive bacterial infection. Nat Med. 2006;12(6):636-641.

3. Spencer JD, et al. Ribonuclease 7 is a potent antimicrobial peptide within the human urinary tract. Kidney Int. 2011;80(2):174-180.

4. Schilling JD, Martin SM, Hung CS, Lorenz RG, Hultgren SJ. Toll-like receptor 4 on stromal and hematopoietic cells mediates innate resistance to uropathogenic Escherichia coli. Proc Natl Acad Sci US A. 2003;100(7):4203-4208.

5. Ganz T. Defensins in the urinary tract and other tissues. J Infect Dis. 2001;183(suppl 1):S41-S42.

6. Saemann MD, et al. Tamm-Horsfall glycoprotein links innate immune cell activation with adaptive immunity via a Toll-like receptor-4-dependent mechanism. J Clin Invest. 2005;115(2):468-475.

7. Paragas $\mathrm{N}$, et al. $\alpha$-Intercalated cells defend the urinary system from bacterial infection. J Clin Invest. 2014;124(7):2963-2976.

8. Goetz DH, Holmes MA, Borregaard N, Bluhm ME, Raymond KN, Strong RK. The neutrophil lipocalin NGAL is a bacteriostatic agent that interferes with siderophore-mediated iron acquisition. Mol Cell. 2002;10(5):1033-1043.

9. Flo $\mathrm{TH}$, et al. Lipocalin 2 mediates an innate immune response to bacterial infection by sequestrating iron. Nature. 2004;432(7019):917-921.

10. Jaillon $\mathrm{S}$, et al. The humoral pattern recognition molecule PTX3 is a key component of innate immunity against urinary tract infection. Immunity. 2014;40(4):621-632.

11. Al-Awqati Q. Cell biology of the intercalated cell in the kidney. FEBS Lett. 2013;587(13):1911-1914.

12. Wall SM. Recent advances in our understanding of intercalated cells. Curr Opin Nephrol Hypertens. 2005;14(5):480-484.

13. Chan CY, St John AL, Abraham SN. Mast cell interleukin-10 drives localized tolerance in chronic bladder infection. Immunity. 2013;38(2):349-359.

14. Mishra J, et al. Neutrophil gelatinase-associated lipocalin (NGAL) as a biomarker for acute renal injury after cardiac surgery. Lancet. 2005; 365(9466):1231-1238.

15. DuBose TD, Alpern RJ. Renal tubular acidosis. In: Valle D, et al., eds. The Online Metabolic and Molecular Bases of Inherited Disease. New York, New York, USA: McGraw-Hill; 2007:Chapter 195. doi:10.1036/ ommbid.228.

16. Raz R, Stamm WE. A controlled trial of intravaginal estriol in postmenopausal women with recurrent urinary tract infections. $N$ Engl J Med. 1993;329(11):753-756.

\title{
Loss of $\mathrm{P}_{2} \mathrm{Y}_{14}$ results in an arresting response to hematological stress
}

\author{
Brian S. Garrison ${ }^{1,2,3}$ and Derrick J. Rossi1,2,3,4
}

${ }^{1}$ Department of Stem Cell and Regenerative Biology, Harvard University, Cambridge, Massachusetts, USA. 2Department of Pediatrics, Harvard Medical School, Boston, Massachusetts, USA. ${ }^{3}$ Program in Cellular and Molecular Medicine, Division of Hematology/Oncology, Boston Children's Hospital, Boston, Massachusetts, USA. ${ }^{4}$ Harvard Stem Cell Institute, Cambridge, Massachusetts, USA.

\begin{abstract}
The regenerative capacity of tissues to recover from injury or stress is dependent on stem cell competence, yet the underlying mechanisms that govern how stem cells detect stress and initiate appropriate responses are poorly understood. In this issue of the JCI, Cho and Yusuf et al. demonstrate that the purinergic receptor $\mathrm{P}_{2} \mathrm{Y}_{14}$ may mediate the hematopoietic stem and progenitor cell regenerative response.
\end{abstract}

\section{Senescence and stem cell decline}

Cellular senescence, a state of permanent irreversible growth arrest, was initially described over half a century ago by Leon-

Conflict of interest: Derrick Rossi has an ownership stake and provides consultation for Moderna Therapeutics.

Citation for this article: J Clin Invest. 2014;

124(7):2846-2848. doi:10.1172/JCI76626. ard Hayflick and Paul Moorhead, who observed that normal human fibroblasts cease to replicate after 50 to 60 cellular divisions (1). This barrier to everlasting cellular proliferation later became termed the "Hayflick limit," denoting the loss of proliferative potential even though the cell remains viable and metabolically active. While this phenomenon was originally connected to long-term in vitro cell propa- gation, cellular senescence is now understood to be a complex mechanism that may limit cell growth as well as prevent cancer in vivo and that can be initiated in response to a variety of cellular stresses, including oxidative damage, telomere shortening, DNA damage, and gene deregulation (2-4).

As with the majority of tissues, the hematopoietic system exhibits signs of age-related decline, including immune dysfunction, decreased red blood cell production, increased incidence of malignancies, and impaired recovery from injury, much of which appears to arise through cell autonomous changes in the HSC compartment (5-8). These age-related changes in the HSC compartment appear to be 


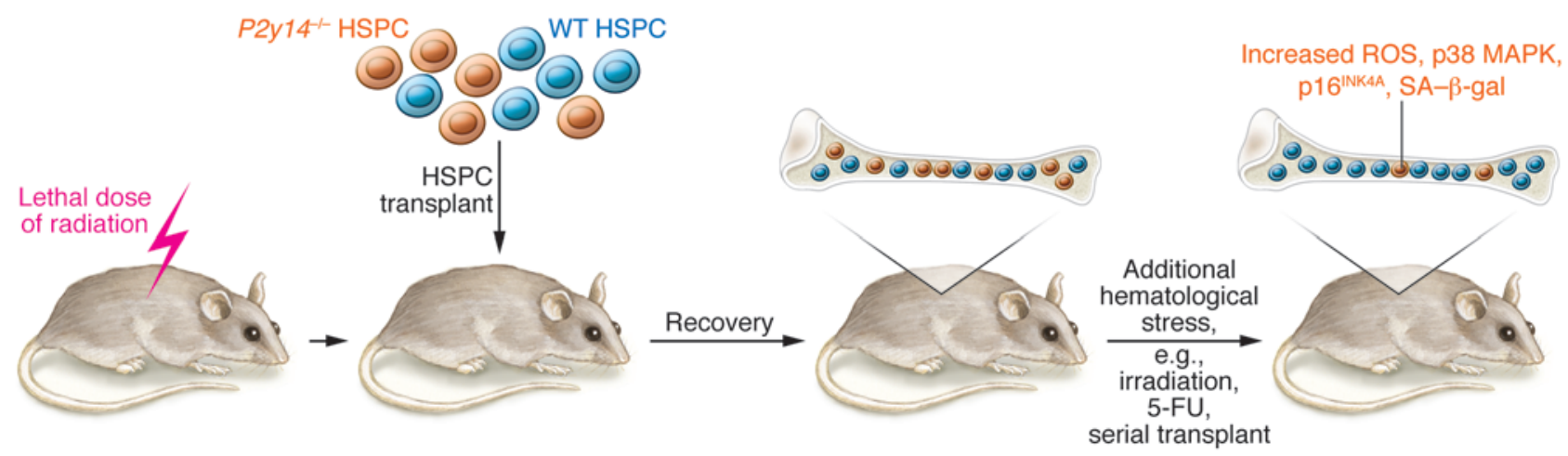

\section{Figure 1}

HSPCs lacking P2Y 14 have reduced functionality. Competitive transplantation of WT and P2Y ${ }_{14}$-deficient HSPCs into an irradiated animal results in equal repopulation of the hematopoietic environment. Following blood reconstitution, $P 2 y 14^{-/-}$HSPCs exhibit a competitive disadvantage if mice are exposed to additional hematological stress, such as irradiation or serial transplantation. Furthermore, in response to stress, $\mathrm{P} \mathrm{Y}_{144^{-}}$ deficient HSPCs show several markers of senescence, including increased ROS, p38 MAPK, p16INK4A, and SA- $\beta$-gal.

driven by diverse processes, including DNA damage accumulation $(9,10)$, loss of cell polarity (11), epigenetic changes of DNA methylation and histone modifications $(12,13)$, and clonal dominance of lineagebiased HSCs (7). While age-related decline in many tissues is thought to coincide with increased cellular senescence of their respective stem and progenitor cell populations (14), in the HSC compartment, it is unclear whether senescence promotes physiological aging, though classical senescence markers, such as $\mathrm{p} 16^{\mathrm{INK} 4 \mathrm{~A}}$, do not appear to be robustly upregulated in aged HSCs $(13,15)$. It should be noted that there is evidence of $\mathrm{p} 16^{\mathrm{INK} 4 \mathrm{~A}}$-dependent modulation of HSC potential under conditions of extreme hematopoietic stress, such as serial transplantation (16).

\section{Loss of $\mathrm{P}_{2} \mathrm{Y}_{14}$ leads to reduced HSC potential in response to stress}

In this issue, Cho, Yusuf, and colleagues provide evidence that stress-induced senescence in hematopoietic stem progenitor cells (HSPCs) is regulated through the G-coupled cell-surface receptor $\mathrm{P}_{2} \mathrm{Y}_{14}$ (17). HSCs give rise to all blood effector cells for the life of an individual, and the capacity to constantly replenish the hematopoietic compartment requires a careful balance among HSC fate decisions, including self renewal, quiescence, apoptosis, and multilineage differentiation. In contrast with HSCs, differentiated effector populations frequently have a short life span, measured in days, resulting in a huge daily cell turnover that necessitates tight homeostatic control of the upstream HSPC populations, where transit amplification occurs.
Under situations of stress, such as irradiation or chemotherapy, a portion of the HSPC pool may be lost, leading to myelosuppression (decreased red cell, white cell, and platelet numbers), and in such cases, the surviving HSPCs must increase self renewal and differentiation to repopulate required cell populations. How HSPCs integrate stress signals to invoke the appropriate stress responses remains unclear. Cho, Yusuf, and colleagues have revealed that $\mathrm{P}_{2} \mathrm{Y}_{14}$ regulates the HSPC response to stress. Specifically, the authors demonstrate that HSPCs lacking $\mathrm{P}_{2} \mathrm{Y}_{14}$ are not at a disadvantage for restoring hematopoietic populations when cotransplanted with equivalent WT HSPCs in lethally irradiated mice under steady state conditions; however, under various stress conditions, including serial transplantation, radiation, and chemotherapy, cells lacking $\mathrm{P}_{2} \mathrm{Y}_{14}$ were less competitive than WT cells. As a result of the stress-induced loss of competitiveness, there was a decline in P2Y ${ }_{14}$-deficient HSPCs and total peripheral blood chimerism (Figure 1). Interestingly, the loss of functionality in $\mathrm{P}_{2} \mathrm{Y}_{14}$-deficient cells occurred concurrently with increased detection of several classical senescence biomarkers, including $\mathrm{p} 16^{\mathrm{INK} 4 \mathrm{~A}}$, greater $\beta$-gal (SA- $\beta$-gal) activity, and increased ROS, implicating cellular senescence as a possible consequence of $\mathrm{P}_{2} \mathrm{Y}_{14}$ deficiency during stress. Furthermore, Cho, Yusuf, and colleagues demonstrated that the enhanced susceptibility to irradiation stress in $\mathrm{P}_{2} \mathrm{Y}_{14}$-deficient HSPCs could be alleviated through administration of the ROS scavenger N-acetyl-cysteine (NAC) or inhibition of p38 MAPK, an important mediator of the ROS-response pathway, indicating that dysfunctional ROS management may be a significant underlying contributor (17).

HSC function has previously been shown to diminish as a consequence of ROS dysregulation, leading to premature exhaustion and shortened lifespan. For example, mice deficient in ataxia telangiectasia mutated (ATM) experience hematopoietic failure, which is largely abrogated by NAC treatment (18). Similarly, deletion of genes encoding forkhead box transcription factors (FoxOs) has been shown to negatively affect HSC function and numbers through increased ROS production and subsequent HSC apoptosis (19-21). Together, these results indicate that increased ROS levels diminish HSC function; therefore, it is likely that the increased ROS detected in $\mathrm{P}_{2} \mathrm{Y}_{14}$-deficient HSPCs is playing an integral role in the observed phenotypes through cellular oxidative damage and perhaps apoptosis, although future work will be needed to elucidate the exact connection between the $\mathrm{P}_{2} \mathrm{Y}_{14}$ receptor and ROS management.

\section{Conclusions and future directions}

Cho, Yusuf, and colleagues have shown that HSPCs lacking the $\mathrm{P}_{2} \mathrm{Y}_{14}$ receptor are compromised in their ability to withstand and recover from several types of stress. The authors make a strong biochemical case for a senescence-based mechanism explaining the diminished function of $\mathrm{P}_{2} \mathrm{Y}_{14}$-deficient HSPCs during stress, though the development of functional assays that uncouple senescence from other processes that diminish HSC potential, such as apoptosis, 
will likely be required to definitively elucidate how $\mathrm{P}_{2} \mathrm{Y}_{14}$ mediates the HSPC stress response $(10,22)$. If $P Y 2_{14}$-deficient HSCs within the animal model system developed by Cho, Yusuf, and colleagues do indeed prove to be functionally senescent, then this could be an exciting model system for studying the onset of stress-induced senescence within the HSC compartment. A better understanding of the regulators of HSC stress response has important implications for regenerative medicine.

\section{Acknowledgments}

D.J. Rossi is a New York Stem Cell Foundation Robertson Investigator.

Address correspondence to: Derrick J. Rossi, 200 Longwood Ave., Warren Alpert Building, Room \#149e, Boston, Massachusetts 02115, USA. Phone: 617.713.8900; Fax: 617.713.8910; E-mail: derrick.rossi@ childrens.harvard.edu.

\footnotetext{
1. Hayflick L, Moorhead PS. The serial cultivation of human diploid cell strains. Exp Cell Res. 1961;25:585-621.

2. Campisi J, d'Adda di Fagagna F. Cellular senescence: when bad things happen to good cells. Nat Rev Mol Cell Biol. 2007;8(9):729-740.
}

3. Kuilman T, Michaloglou C, Mooi WJ, Peeper DS. The essence of senescence. Genes Dev. 2010; 24(22):2463-2479.

4. Salama R, Sadaie M, Hoare M, Narita M. Cellular senescence and its effector programs. Genes Dev. 2014;28(2):99-114.

5. Rossi DJ, et al. Cell intrinsic alterations underlie hematopoietic stem cell aging. Proc Natl Acad Sci US A. 2005;102(26):9194-9199.

6. Dykstra B, Olthof S, Schreuder J, Ritsema M, de Haan G. Clonal analysis reveals multiple functional defects of aged murine hematopoietic stem cells. J Exp Med. 2011;208(13):2691-2703

7. Beerman I, et al. Functionally distinct hematopoietic stem cells modulate hematopoietic lineage potential during aging by a mechanism of clonal expansion. Proc Natl Acad Sci U S A. 2010; 107(12):5465-5470

8. Pang WW, et al. Human bone marrow hematopoietic stem cells are increased in frequency and myeloidbiased with age. Proc Natl Acad Sci U S A. 2011; 108(50):20012-20017.

9. Rossi DJ, Bryder D, Seita J, Nussenzweig A, Hoeijmakers J, Weissman IL. Deficiencies in DNA damage repair limit the function of haematopoietic stem cells with age. Nature. 2007 447(7145):725-729.

10. Beerman I, Seita J, Inlay MA, Weissman IL, Ross DJ. Quiescent hematopoietic stem cells accumulate DNA damage during aging that is repaired upon entry into cell cycle. Cell Stem Cell. 2014;pii:S19345909(14)00153-2.

11. Florian MC, et al. Cdc42 activity regulates hematopoietic stem cell aging and rejuvenation. Cell Stem Cell. 2012;10(5):520-530.

12. Beerman I, et al. Proliferation-dependent alterations of the DNA methylation landscape underlie hematopoietic stem cell aging. Cell Stem Cell. 2013; 12(4):413-425.

13. Sun D, et al. Epigenomic profiling of young and aged HSCs reveals concerted changes during aging that reinforce self-renewal. Cell Stem Cell. 2014; 14(5):673-688.

14. Sperka T, Wang J, Rudolph KL. DNA damage checkpoints in stem cells, ageing and cancer. Nat Rev Mol Cell Biol. 2012;13(9):579-590.

15. Attema JL, Pronk CJ, Norddahl GL, Nygren JM, Bryder D. Hematopoietic stem cell ageing is uncoupled from p16 INK4A-mediated senescence. Oncogene. 2009;28(22):2238-2243.

16. Janzen V, et al. Stem-cell ageing modified by the cyclin-dependent kinase inhibitor p16INK4a. Nature. 2006;443(7110):421-426

17. Cho J, et al. Purinergic $\mathrm{P}_{2} \mathrm{Y}_{14}$ receptor modulates stress-induced hematopoietic stem/progenitor cell senescence. J Clin Invest. 2014;124(7):3159-3171.

18. Ito $\mathrm{K}$, et al. Regulation of reactive oxygen species by Atm is essential for proper response to DNA double-strand breaks in lymphocytes. J Immunol. 2007; 178(1):103-110.

19. Tothova $Z$, et al. FoxOs are critical mediators of hematopoietic stem cell resistance to physiologic oxidative stress. Cell. 2007;128(2):325-339.

20. Miyamoto K, et al. Foxo3a is essential for maintenance of the hematopoietic stem cell pool. Cell Stem Cell. 2007;1(1):101-112.

21. Yalcin S, et al. Foxo3 is essential for the regulation of ataxia telangiectasia mutated and oxidative stress-mediated homeostasis of hematopoietic stem cells. J Biol Chem. 2008;283(37):25692-25705.

22. Shao L, et al. Total body irradiation causes longterm mouse BM injury via induction of HSC premature senescence in an Ink4a- and Arf-independent manner. Blood. 2014;123(20):3105-3115

\title{
Twisting mice move the dystonia field forward
}

\author{
Åsa Petersén ${ }^{1}$ and Deniz Kirik² \\ ${ }^{1}$ Translational Neuroendocrine Research Unit and ${ }^{2}$ Brain Repair and Imaging in Neural Systems (B.R.A.I.N.S.) Unit, \\ Department of Experimental Medical Sciences, Lund University, Lund, Sweden.
}

\begin{abstract}
A common form of the hyperkinetic movement disorder dystonia is caused by mutations in the gene TOR1A (located within the DYT1 locus), which encodes the ATPase torsinA. The underlying neurobiological mechanisms that result in dystonia are poorly understood, and progress in the field has been hampered by the absence of a dystonia-like phenotype in animal models with genetic modification of Tor1a. In this issue of the JCI, Liang et al. establish the first animal model with a dystonic motor phenotype and link torsinA hypofunction to the development of early neuropathological changes in distinct sensorimotor regions. The findings of this study will likely play an important role in elucidating the neural substrate for dystonia and should stimulate systematic neuropathological and imaging studies in carriers of TOR $1 A$ mutations.
\end{abstract}

\section{Neurological disorders and the need for animal models}

For many brain disorders, identification and characterization of the underlying

Conflict of interest: Deniz Kirik receives financial compensation in the form of retainer fees, milestones, and royalty payments from Genepod Therapeutics $A B$ and receives research grant support from ParkCell AB.

Citation for this article: J Clin Invest. 2014;

124(7):2848-2850. doi:10.1172/JCI76624. neurobiological mechanisms remains a challenge for clinicians and scientists. Lack of defined neural substrates and an understanding of the pathways responsible for neurological and psychiatric symptoms has limited the development of novel therapies, which are urgently needed to improve the care and quality of life of affected individuals. In this issue, Liang and collaborators present animal models that recapitulate the major clinical symptomatology of dystonia (1). The study by Liang and colleagues represents an important leap forward for the dystonia research field.

\section{Dystonia: the twists and turns}

Dystonia is characterized by sustained or intermittent muscle contractions that cause abnormal, often repetitive, twisting movements and postures and is now recognized as a heterogenous group of hyperkinetic movement disorders. The term dystonia was coined in 1911 by Herman Oppenheim, who used "dystonia musculorum deformans" to describe a childhoodonset form of generalized dystonia (2). These disorders have traditionally been classified as either primary or secondary dystonias. Primary dystonia is considered to only present with tremor or myoclonus as an additional neurological symptom 